It's Contagious! The Effects of Gamifying Refutation Texts on Emotions and Learning

Date submitted: 15 September 2021

Gregory J. Trevors

University of South Carolina

\author{
Cierra Chong \\ Danielle Graham \\ Justin Kogler \\ Farhaan Ladhani \\ Kevin Melo \\ Ornab Momin \\ Jordan Morello \\ Tanya Whyte \\ Sean Willett \\ Kara Wilson Oliver \\ Ben Windeler \\ Sam Wollenberg \\ Digital Public Square
}

Corresponding Author:

Gregory J. Trevors

University of South Carolina

115A Wardlaw College

820 Main Street

Columbia, SC

29208

trevorsg@mailbox.sc.edu 


\begin{abstract}
The current study investigated the effects of gamifying refutations on emotions and learning. Refutations have a substantial body of evidence supporting their use to correct misconceptions, yet reduced efficacy has been observed for some topics that induce negative emotional reactions. We tested whether gamification could mitigate these limits given that it capitalizes on positive affective engagement. From May to December 2020, approximately 200,000 individuals were recruited from social media in Canada to engage with a non-game interactive survey as a control or a fully gamified platform focused on correcting COVID-19 misconceptions. Gamification resulted in higher levels of happiness and anxiety and lower levels of anger and skepticism in response to having misconceptions corrected by refutations. Further, participants who engaged with gamified refutations retained correct information after a brief period. Finally, positive emotions and anxiety positively predicted and negative emotions largely negatively predicted retention and support for related public health policies. Implications for scaling up and reinforcing the benefits of refutations for public engagement with science are discussed.
\end{abstract}


Traditionally, governments and related organizations rely on direct broadcasts of key information via print, television, or online media to educate their citizens on issues in the public interest. However, the public may have misconceptions about several of these subjects, such as immigration, climate change, and pandemics, which both undermine informed decision making and are often unaffected by a simple broadcasting strategy. Thus, new methods of communicating and engaging with the public are needed to address misconceptions and empower informed actions.

In the following, we investigated the effects of embedding refutation texts into a digital gamified environment. Refutation texts are one well-known tool to correct misconceptions in traditional educational settings, yet challenges exist to scaling it up to address public misconceptions within present-day debates among large, diverse audiences. We describe the potential of gamification as a novel approach to address these challenges and capitalize on individuals' inherent motivational and emotional strengths. We tested this approach to correcting misconceptions against the backdrop of the COVID-19 pandemic, which spawned many new misconceptions and presented a historic challenge to traditional communication efforts.

\section{Infodemic Context}

The novel coronavirus pandemic generated unprecedent global attention and concern. The gap between what little was known early on about its risks, symptoms, transmission, prevention, and treatments and what individuals desired to know was filled with rapidly evolving scientific evidence and government policies along with estimates and predictions, rumors and speculation, and mis- and disinformation. The sum of this informational surge led the WHO Director-General to state in February 2020 that "we're not just fighting an epidemic; we're fighting an infodemic" (WHO, 2020). Infodemics are an overabundance of information, including false information, 
during a disease outbreak that leads to confusion, mistrust, and potentially dangerous behaviors (WHO, 2021).

The infodemic is in part driven by the fact that public health issues are emotionally charged and value laden. Facing a barrage of news reports about an infectious disease pandemic and the disruptions it wrought is anxiety-provoking (Abadi et al., 2021; Neill et al., 2021), and anxiety itself in turn drives greater information-seeking (Jungmann \& Witthoft, 2020). Further, despite in many cases being necessary, several public health responses to the pandemic were still severe disruptions to individuals' economic, social, and personal lives. As a result, multiple stakeholders held conflicting incentives and ideas about the high-stakes issue of the best course of action, which frequently led to angry confrontations between values and politicization (Gadarian et al., 2021; Pew, 2021; Smith et al., 2021; Trevors \& Duffy, 2020). Taken together, the infodemic and the strong emotional reactions it elicited presented a historic challenge to public health communication, which provided space for misconceptions to proliferate ${ }^{1}$ and necessitated new approaches to public education (Han et al., 2020; Li et al., 2020).

\section{Belief Change via Refutation Text}

Refutation texts are an effective, short-term, and adaptable countermeasure to misconceptions that have strong theoretical and empirical support. Refutations are typically brief documents with a specific text structure that explicitly references an incorrect belief, refutes it, and presents several claims that reinforce the correct understanding as a substitute explanation (Hynd, 2001). In so doing, Kendeou and colleagues (2013, 2014, 2019) theorize that refutation texts promote a specific sequence of cognitive processes that result in knowledge revision. Most notably, this includes instigating competitive cognitive conflict between correct and incorrect

\footnotetext{
${ }^{1}$ For instance, an analysis of the most viewed YouTube videos on COVID-19 found that 1 in 4 contained false information, which together had already garnered 62 million views by March 2020 (Li et al, 2020).
} 
understandings. Conflict is resolved when the quantity and quality of correct supporting explanations presented in refutations is encoded in and dominates the same memory network as the original incorrect belief. After reading a refutation text, outdated incorrect beliefs no longer intrude in recall or decision-making tasks since limited attention is privileged for the newly constructed, dominant correct conception.

With few notable exceptions, empirical research on refutations largely supports this theoretical account. At the point of contradicting a misconception, refutations are found to trigger cognitive conflict and epistemic emotions of surprise, curiosity, and confusion (Kendeou et al., 2019; Kendeou et al., 2013; Trevors, 2021; Trevors et al., 2017), which are associated with detecting and resolving knowledge inconsistencies via greater informational seeking, critical thinking, and elaborative learning processes (D’Mello et al., 2014; Foster \& Keane, 2019; Muis, Chevrier, et al., 2018; Muis, Sinatra, et al., 2018). Refutations are associated with higher levels of epistemic judgements regarding the plausibility, credibility, and quality of refutational evidence, which in turn predict revising incorrect beliefs (Flemming et al., 2020; Lombardi et al., 2016; Muis et al., 2020). Additionally, refutations increase metacognitive awareness of the conflict between old and new interpretations and of individuals' own understanding (Mason et al., 2017; Pieschl et al., 2021; Prinz et al., 2019), which are integral processes in changing prior beliefs (Vosniadou et al., 2001). As a result of these cognitive, affective, and metacognitive processes, refutations are consistently associated with gaining more accurate knowledge as well as other positive changes in related attitudes and policy support (Aguilar et al., 2019; Thacker et al., 2020; Tippett, 2010; Walter \& Murphy, 2018).

However, for several other topics and groups of individuals, refutations and related factchecks are less effective. This is possibly due to distinct sets of motivational and emotional 
reactions. Despite improving the accuracy of the average individual's beliefs, meta-analytic studies show that the effect of refutational-like fact-checks is weaker for real-world misconceptions, political topics, and counter-attitudinal corrections (Walter et al., 2020; Walter \& Murphy, 2018). The reduced efficacy in these areas suggests that not all individuals are engaging in rational belief updating processes when refutations are applied to topics that are emotionally charged or touch on personally relevant values. Two routes that implicate different motivational and emotional processes may explain these diminished refutational effects.

First, in such cases where an individual perceives that their values are under threat, they may be inclined to engage in motivated reasoning, a well-studied phenomenon in which individuals use their intellectual abilities to protect their valued beliefs at the expense of forming accurate beliefs (Kaplan et al., 2016; Lodge \& Taber, 2013). Affective theory suggests that emotions occur in response to relevant stimuli and have tendencies to motivate subsequent actions (e.g., flight or fight), such as anger in response to perceived violations of moral values and desire for retribution (Haidt, 2003). Indeed, in belief change research, corrective messages perceived to threaten valued beliefs have been found to lead to doubt, anxiety, and anger, which in turn predicted maintaining false beliefs by rejecting corrections (Nauroth et al., 2014, 2015; Trevors, 2021; Trevors \& Duffy, 2020; Trevors et al., 2016).

Second, individuals may be motivated to avoid engaging with refutational message at all. Some topics like climate change or pandemics provoke fear, anger, or despair (Manning \& Clayton, 2018; Renström \& Bäck, 2021); many individuals do not enjoy interacting with political topics (Klar et al., 2018); and all conflicts with prior beliefs are inherently unpleasant (Dignath et al., 2020). Together, refutations of emotionally charged or politicized topics have low hedonic 
utility, a condition in information-seeking theory that asserts that, all else being equal, individuals will be motivated to avoid information that induces unpleasant affect (Sharot \& Sunstein, 2020).

In sum, these differing sets of negative emotional reactions to refutations are clearly problematic for belief change interventions. Learning from refutations is typically successful and associated with higher levels of positive emotions and lower negative emotions (Broughton et al., 2013; Heddy et al., 2017; Thacker et al., 2020). In contrast, there may exist multiple negative affective pathways that blunt the effectiveness of refutations on emotionally charged and value laden topics. This is troubling because these same topics often represent some of the most significant and urgent issues facing society, such as climate change or vaccinations, where consensus on factual information is a prerequisite for collective actions. Thus, with the goal of enhancing and extending the benefits of refutations to more topics and individuals, we explored whether timely and critical corrections could be effectively delivered - and negative affect mitigated - by gamifying a belief change intervention.

\section{Adaptive Affective Engagement via Gamification}

Gamification refers to the process of adding elements and mechanics of game play (e.g., challenges, competition, progress, feedback) into traditional educational contexts to take capitalize on individuals' inherent motivational and emotional strengths (Deterding et al., 2011; Sailer et al., 2017; Sardi et al., 2017). Gamification fosters intrinsic motivation and positive affect (e.g., enjoyment, interest) and supports individuals' needs for autonomy since the process proceeds under their control (Ryan \& Deci, 2017). As such, it stands in contrast to traditional direct routes of persuasion that may be perceived as overly controlling (Steindl et al., 2015). The indirect route of content engagement in gamified platforms promotes learning, as well as changes in belief and behavior (Alahäivälä \& Oinas-Kukkonen, 2016; Hamari et al., 2016; Petty \& Cacioppo, 2012). 
There is a long history of applying gamification to augment learning but recently it has also been successfully used to proactively prevent forming false beliefs from online misinformation with digital literacy training. Roozenbeek, van der Linden, and colleagues (Basol et al., 2020; Maertens et al., 2020; Roozenbeek \& van der Linden, 2019) found that participants recruited through a university press release and BBC news coverage were better able to recognize unreliable news items after playing a game that exposed them to common strategies used in creation of misinformation. Although a useful tool as a part of a multi-layer defense against misinformation (van der Linden, 2019), pre-emptive debunking may not be relevant for specific misconceptions once formed. Further, samples in this research were recruited from reputable news sources and often skewed toward younger, liberal, and well-educated. In contrast, individuals susceptible to misinformation tend to be older, conservative, less educated, and obtain their news from less reliable sources such as social media (Brashier \& Schacter, 2020; Guess et al., 2019; Pan et al., 2021; Yang et al., 2021).

In sum, given the potential for direct refutations to trigger motivated reasoning and/or low hedonic utility among some individuals and topics, a direct broadcast of corrections is not likely to attain optimal success, allowing critical misinformation to persist. Thus, there is promising potential to transfer gamification benefits to belief change interventions. Further, there is also an opportunity to test this proposition directly on social media platforms, which are a more naturalistic context to support populations vulnerable to misinformation.

\section{Current Study}

The purpose of the current research was to empirically test the assumption that gamification of refutations leads to adaptive cognitive and emotional engagement positively linked to belief change. This assumption was tested with a novel digital game focused on combating several 
COVID-19 misconceptions that was designed and widely distributed in Canada in 2020. Three research questions were addressed:

1. Do individuals retain gamified refutation information in memory?

2. Does gamification increase positive and decrease negative emotions?

3. Do emotional reactions to gamified refutations predict information retention and support for related policies?

\section{Method}

\section{Sample}

From May to June 2020, participants were recruited to engage with an interactive online survey that served as a non-gamified control. Participants were recruited from advertisements on social media platforms in Canada. During this time, 19,493 unique sessions were initiated, from which 11,486 individuals answered at least one knowledge question and 7,831 provided emotional reactions.

From August to December 2020, participants were recruited via the same method to play the fully gamified intervention. During this time, 180,741 unique sessions were initiated that provided an answer at least one knowledge question, 67,302 answered a repeated knowledge question, 22,918 provided emotional reactions, 37,383 responded to at least one policy question, and approximately 26,000 opted-in to partially or fully disclose their demographic information at the end of the game (Tables 1-3).

\section{Materials and Procedure}

Interactive survey control. An interactive online survey was distributed to both assess the prevalence of misconceptions among the public and emotional reactions within a non-gamified context. The survey consisted of a possible two dozen true and false claims about COVID-19 and 
asked participants to indicate whether they thought each was true or false. Immediately following their response, they received the correct feedback ("Correct!" or "Wrong”) and brief explanation that followed refutation design principles to include multiple reinforcing facts (Kendeou \& O'Brien, 2014; Kendeou et al., 2013). Additionally, participants were asked "How does this information make you feel?" and given four emoji to choose from: happy, angry, anxious, and skeptical. Refutations were carried forward to the full gamified intervention if either of two conditions applied: (1) the research team determined there were meaningful levels of incorrect responses (e.g., < $90 \%$ correct on a particular claim), indicating possible presence of misconceptions; or (2) if a medical epidemiologist on the research team determined that acting upon a particular misconception posed serious risk to individuals or communities (e.g., reliance on alcohol to disinfect oneself or on herd immunity as a mitigation strategy).

Digital game design. The design of It's Contagious! (itscontagiousgame.com; Figure 1) followed gamification design principles to motivate and positively engage participants via game elements and mechanics: playful design, specific goal, challenge, personalized experience, visible progress, rapid feedback, freedom of choice, and accrual grading (points) (Deterding et al., 2011). Participants played through the digital game on desktop or mobile devices and progressed through a possible two dozen content pages ("cards"), each presenting one prevalent misinformation or fact about COVID-19 [e.g., "COVID-19 has caused fewer deaths than the flu (influenza) would typically cause in a year" (false)]. COVID-19 misconceptions were identified from the control survey, news reports, and social listening (i.e., collecting data from various social media platforms and forums on a set of topics and key terms related to COVID-19 misconceptions).

Refutation and retention. Participants were asked to indicate their belief in the veracity of the COVID-19 claims by swiping left or right. The following screen presented immediate 
feedback on their response, which followed evidence-based practices for robust misinformation correction (Kendeou \& O'Brien, 2014; Kendeou et al., 2013), including refutation and accessible explanation that reinforced the best available scientific evidence obtained from expert sources (e.g., CDC). Refutations and corrective explanations were vetted by the medical epidemiologist for accuracy and completeness. As a measure of knowledge retention, participants were asked to respond to a second presentation of a question they originally answered incorrectly with the prompt "Do you remember?"

Emotional reactions, policy support, and demographics. Points displayed on a scoreboard were awarded or removed for correct and incorrect responses. Depending on point totals, players may go up or down eight ranks (i.e., "Newb" to "Genius"). Importantly, participants could recover a lost rank by responding to additional questions, which included emotional reactions to refutations via emoji rating scale (i.e., happy, angry, anxious, skeptical) and support or opposition to several public health policies (e.g., face mask mandates) measured on a 1-5 Likert scale. Recovery questions were prefaced with the following message: "Recover your rank! There's no right or wrong answer to the following questions. Please just answer honestly!" Finally, participants could opt into self-disclosing demographic details (i.e., age, gender, race, and ethnicity).

\section{Results}

Descriptive and correlational statistics between primary study variables are reported in Table 4. The number of correct responses to questions were averaged as a measure of participants' prior COVID-19 knowledge. The proportion of emotional reactions across all content was extracted for each of the four emotions. Finally, public health policy support across several policies was averaged into a single value. 


\section{Learning from Gamified Refutations}

To answer the first research question whether individuals retain gamified refutation information, responses to the repeated question were analyzed. Of the 67,302 players who provided a response to a repeated question that they initially answered incorrectly, approximately $87 \%$ provided the correct response. A one-sample $t$ test showed that this level of performance was significantly higher than chance (i.e., 50\%), $t(67301)=284.09, p<.001, d=1.10$, which reflects large effect of retention of refutation information.

\section{Effect of Gamification on Emotional Reactions}

To answer the second research question whether gamification led to an increase in positive and decrease in negative emotions, we compared average proportional emotional responses to refutations between control and gamified conditions (Table 5). Given the differences in content between conditions, only emotional reactions to 13 refutations that were consistent between control and gamified platforms were analyzed for differences. Compared to the non-game interactive control survey, happy and anxious reactions were higher, and anger and skepticism were lower in the digital game intervention (absolute Cohen's $d$ values ranged .04 to $.16)$, which held true after controlling for prior knowledge ( $p$ s $>.005)$. These results suggest that gamification was largely associated with increased positive and decreased negative emotions on the same refutation content, with an increase in anxiety in the gamified condition as an exception.

\section{Relations Between Emotions and Key Outcomes}

Finally, to answer the third research question whether emotional reactions to refutations predict retention and support for related policies, in separate hierarchical linear regressions we regressed retention and policy support on correct responses in the first step and happy, anger, 
anxiety, and skepticism separately in second steps. Average number of correct responses as a measure of prior COVID-19 knowledge was a positive predictor of overall retention $(\beta=.19, p<$ $.001)$ and policy support $(\beta=.22, p<.001)$ in the first step. Beyond the effect of prior knowledge, happiness was a consistently positive predictor of retention $(\beta=.05, p<.001)$ and policy support $(\beta=.11, p<.001)$; anger was a consistently negative predictor of retention $(\beta=-.03, p=.001)$ and policy support $(\beta=-.04, p=.001)$; likewise, skepticism negatively predicted retention $(\beta=-.04, p$ $<.001)$ and policy support $(\beta=-.21, p<.001)$; and anxiety was a positive predictor of policy support only $(\beta=.09, p<.001)$. Across regressions, with the exception of anxiety, the addition of emotions into regression models resulted in significantly improved predictions of retention $\left(\Delta F_{\mathrm{s}}(1\right.$, $7516)=20.53-47.55, p \mathrm{~s}<.001)$ and all emotions improved predictions of policy support $(\Delta F \mathrm{~s}(1$, $22251)=40.16-1049.32, p s<.001)$. These results indicate that beyond the large effect of prior knowledge, emotional reactions to gamified refutations were significant and unique predictors of correct information retention and policy support.

\section{Discussion}

The current study investigated the effects of gamifying refutations on emotions and learning. Refutations have a substantial body of evidence supporting their use to correct misconceptions. However, reduced efficacy is observed for emotionally charged or value laden topics that reflect some of the most urgent issues facing society, possibly due to negative emotional reactions to refutations. We proposed that gamification could mitigate these limits given that it capitalizes on positive affective engagement. The current results supported this overall contention. Gamification resulted in higher levels of happiness and anxiety and lower levels of anger and skepticism in response to having misconceptions corrected by refutations. Participants who engaged with gamified refutations were able to retain correct information after a brief period. 
Finally, positive emotions and anxiety positively predicted and negative emotions largely negatively predicted retention and support for related public health policies.

\section{Refuting Misconceptions with Digital Games}

Consistent with previous research, refutations that were embedded into a gamified context resulted in a large effect of retention of correct information, a larger proportion of positive emotions, and a generally smaller proportion of negative emotional reactions to refutations. These results are noteworthy considering recent meta-analyses showing diminished (though still often significant) effects of refutations and fact-checks on real-world, politicized, or counter-attitudinal topics. We theorized that reduced efficacy may be due to motivated reasoning to protect valued - though inaccurate - prior beliefs, or low hedonic utility leading people to avoid engaging with unpleasant corrections on sensitive topics. The current results therefore are a demonstration that gamified refutations may be an effective alternative to correcting misconceptions on such topics. Roughly 9 out of 10 players were able to correctly recall newly presented true information about COVID-19 when prompted after several new rounds of questions, which suggests that refutation information was successfully stored and not simply maintained in short-term memory. Recall that retention questions were only asked for a question that participants initially provided an incorrect response, indicating that participants either held a misconception or did not know the answer. As such, this finding indicates that the current gamified refutations increased accurate knowledge. Although future research should further explore the precise nature of prior beliefs and the longer-term duration of knowledge acquisition, the present results show an early and promising potential to efficiently educate the public on a large scale with digital games. 
Further, we found that positive and negative emotional reactions to refutations were significant unique predictors of subsequent retention and policy support beyond the large effect of prior knowledge. This supports our central contention that increasing positive engagement and decreasing negative affective engagement of belief correction content via gamification may be important and opposite drivers of promoting uptake of accurate information on controversial socioscientific content. Interestingly, anxiety was found to have a unique pattern of relations among outcome variables distinct from other negative emotions since it positively predicted support for public health policies. Negative activating emotions like anxiety have a complex relationship to learning outcomes as it has been linked to both approach and avoidance motivation (Pekrun, 2006). In the current context focused on COVID-19, higher levels of anxiety have been found to predict engagement in more public health-compliant behaviors (e.g., hand washing and social distancing) (Harper et al., 2021). Higher anxiety may therefore reflect a recalibration of perceived risk from the pandemic itself rather than rejection of refutations. That is, corrective information about the severity and susceptibility of COVID-19 may have led players to become less complacent and form more accurate perceptions of disease risk. Along with happiness, anxiety was found to increase because of gamification, though it should be noted that happiness was still the predominant emotional experience in the game environment. Given that the refutation content was the same between control and gamified conditions for statistical comparison, a higher level of anxiety may be attributed to an increase level of attention to the content in the gamified condition (and thus greater revision of risk perceptions) versus a relatively shallower level of attention in the interactive survey control. However, speculations on cognitive engagement during game play require future investigation.

\section{Conclusions}


Theoretically, the study sought to advance fundamental knowledge about digital learning contexts and affective processes involved in successful corrections of misconceptions about polarized, emotionally laden topics. Recent interventions to correct such misconceptions have revealed some limits of existing methods and theories, which have largely relied on an information deficit model of science communication (Sinatra \& Seyranian, 2015; Suldovsky, 2016). The current proposal represents a new interactive approach to misconception correction that augments how individuals affectively interact with challenging educational content, which may overcome limitations of prior direct routes of communication. Better understanding of the learning mechanisms involved in correcting challenging misconceptions gained from the current study will enable improved interventions more broadly. Methodologically, the large sample supports conclusions with strong external validity and demonstrated potential to support public engagement with science at a large scale. Practically, the integration of two heretofore separate lines of research - belief change and gamification - produced a digital platform with strong potential for future growth. 


\section{References}

Abadi, D., Arnaldo, I., \& Fischer, A. (2021, 2021-August-31). Anxious and Angry: Emotional Responses to the COVID-19 Threat [Original Research]. Frontiers in psychology, 12(3516). https://doi.org/10.3389/fpsyg.2021.676116

Aguilar, S. J., Polikoff, M. S., \& Sinatra, G. M. (2019, Jul). Refutation Texts: A New Approach to Changing Public Misconceptions About Education Policy. Educational Researcher, 48(5), 263-272. https://doi.org/10.3102/0013189x19849416

Alahäivälä, T., \& Oinas-Kukkonen, H. (2016). Understanding persuasion contexts in health gamification: A systematic literature review of gamified health behavior change support systems literature. International Journal of Medical Informatics.

Basol, M., Roozenbeek, J., \& van der Linden, S. (2020). Good news about bad news: Gamified inoculation boosts confidence and cognitive immunity against fake news. Journal of cognition, 3(1).

Brashier, N. M., \& Schacter, D. L. (2020). Aging in an era of fake news. Current directions in psychological science, 29(3), 316-323.

Broughton, S. H., Sinatra, G. M., \& Nussbaum, E. M. (2013). "Pluto has been a planet my whole life!" Emotions, attitudes, and conceptual change in elementary students' learning about Pluto's reclassification. Research in Science Education, 43(2), 529-550.

D’Mello, S., Lehman, B., Pekrun, R., \& Graesser, A. (2014). Confusion can be beneficial for learning. Learning and Instruction, 29, 153-170.

Deterding, S., Dixon, D., Khaled, R., \& Nacke, L. (2011). From game design elements to gamefulness: defining" gamification". Proceedings of the 15th international academic MindTrek conference: Envisioning future media environments,

Dignath, D., Eder, A. B., Steinhauser, M., \& Kiesel, A. (2020). Conflict monitoring and the affective-signaling hypothesis-An integrative review. Psychonomic Bulletin \& Review, 27(2), 193-216.

Flemming, D., Kimmerle, J., Cress, U., \& Sinatra, G. M. (2020, Jan). Research is Tentative, but That's Okay: Overcoming Misconceptions about Scientific Tentativeness through Refutation Texts. Discourse Processes, 57(1), 17-35. https://doi.org/10.1080/0163853x.2019.1629805

Foster, M. I., \& Keane, M. T. (2019). The role of surprise in learning: different surprising outcomes affect memorability differentially. Topics in cognitive science, 11(1), 75-87. 
Gadarian, S. K., Goodman, S. W., \& Pepinsky, T. B. (2021). Partisanship, health behavior, and policy attitudes in the early stages of the COVID-19 pandemic. PloS one, 16(4), e0249596.

Guess, A., Nagler, J., \& Tucker, J. (2019, Jan). Less than you think: Prevalence and predictors of fake news dissemination on Facebook. Science Advances, 5(1), Article eaau4586. https://doi.org/10.1126/sciadv.aau4586

Haidt, J. (2003). The moral emotions. In Handbook of affective sciences. (pp. 852-870). Oxford University Press.

Hamari, J., Shernoff, D. J., Rowe, E., Coller, B., Asbell-Clarke, J., \& Edwards, T. (2016). Challenging games help students learn: An empirical study on engagement, flow and immersion in game-based learning. Computers in Human Behavior, 54, 170-179.

Han, J., Cha, M., \& Lee, W. (2020). Anger contributes to the spread of covid-19 misinformation. Harvard Kennedy School Misinformation Review, 1(3).

Harper, C. A., Satchell, L. P., Fido, D., \& Latzman, R. D. (2021). Functional Fear Predicts Public Health Compliance in the COVID-19 Pandemic. International Journal of Mental Health and Addiction. https://doi.org/10.1007/s11469-020-00281-5

Heddy, B. C., Danielson, R. W., Sinatra, G. M., \& Graham, J. (2017). Modifying Knowledge, Emotions, and Attitudes Regarding Genetically Modified Foods. Journal of Experimental Education, 85(3), 513-533. https://doi.org/10.1080/00220973.2016.1260523

Jungmann, S. M., \& Witthoft, M. (2020, Jun). Health anxiety, cyberchondria, and coping in the current COVID-19 pandemic: Which factors are related to coronavirus anxiety? Journal of Anxiety Disorders, 73, Article 102239. https://doi.org/10.1016/j.janxdis.2020.102239

Kaplan, J. T., Gimbel, S. I., Dehghani, M., Immordino-Yang, M. H., Sagae, K., Wong, J. D., Tipper, C. M., Damasio, H., Gordon, A. S., \& Damasio, A. (2016). Processing Narratives Concerning Protected Values: A Cross-Cultural Investigation of Neural Correlates. Cerebral Cortex, 27(2), 1428-1438. https://doi.org/10.1093/cercor/bhv325

Kendeou, P., Butterfuss, R., Kim, J., \& Van Boekel, M. (2019, Jan). Knowledge revision through the lenses of the three-pronged approach. Memory \& Cognition, 47(1), 33-46. https://doi.org/10.3758/s13421-018-0848-y

Kendeou, P., \& O'Brien, E. J. (2014). The Knowledge Revision Components (KReC) framework: Processes and mechanisms.

Kendeou, P., Smith, E. R., \& O'Brien, E. J. (2013). Updating during reading comprehension: Why causality matters. Journal of Experimental Psychology: Learning, Memory, and Cognition, 39(3), 854. 
Klar, S., Krupnikov, Y., \& Ryan, J. B. (2018). Affective polarization or partisan disdain? Untangling a dislike for the opposing party from a dislike of partisanship. Public opinion quarterly, 82(2), 379-390.

Li, H. O.-Y., Bailey, A., Huynh, D., \& Chan, J. (2020). YouTube as a source of information on COVID-19: a pandemic of misinformation? BMJ Global Health, 5(5), e002604.

Lodge, M., \& Taber, C. S. (2013). The rationalizing voter. Cambridge University Press.

Lombardi, D., Danielson, R. W., \& Young, N. (2016, Aug). A plausible connection: Models examining the relations between evaluation, plausibility, and the refutation text effect. Learning and Instruction, 44, 74-86. https://doi.org/10.1016/j.learninstruc.2016.03.003

Maertens, R., Roozenbeek, J., Basol, M., \&, \& van der Linden, S. (2020). Long-term effectiveness of inoculation against misinformation: Three longitudinal experiments. Journal of Experimental Psychology: Applied., 27(1), 1-16.

Manning, C., \& Clayton, S. (2018). Threats to mental health and wellbeing associated with climate change. In Psychology and climate change (pp. 217-244). Elsevier.

Mason, L., Baldi, R., Di Ronco, S., Scrimin, S., Danielson, R. W., \& Sinatra, G. M. (2017, Apr). Textual and graphical refutations: Effects on conceptual change learning. Contemporary Educational Psychology, 49, 275-288. https://doi.org/10.1016/j.cedpsych.2017.03.007

Muis, K. R., Chevrier, M., \& Singh, C. A. (2018). The role of epistemic emotions in personal epistemology and self-regulated learning. Educational Psychologist, 53(3), 165-184. https://doi.org/10.1080/00461520.2017.1421465

Muis, K. R., Etoubashi, N., \& Denton, C. A. (2020, Jul). The catcher in the lie: The role of emotions and epistemic judgments in changing students' misconceptions and attitudes in a post-truth era. Contemporary Educational Psychology, 62, Article 101898. https://doi.org/10.1016/j.cedpsych.2020.101898

Muis, K. R., Sinatra, G. M., Pekrun, R., Winne, P. H., Trevors, G., Losenno, K. M., \& Munzar, B. (2018). Main and moderator effects of refutation on task value, epistemic emotions, and learning strategies during conceptual change. Contemporary Educational Psychology, 55, 155-165. https://doi.org/10.1016/j.cedpsych.2018.10.001

Nauroth, P., Gollwitzer, M., Bender, J., \& Rothmund, T. (2014). Gamers against science: The case of the violent video games debate. European Journal of Social Psychology, 44(2), 104-116.

Nauroth, P., Gollwitzer, M., Bender, J., \& Rothmund, T. (2015). Social identity threat motivates science-discrediting online comments. PloS one, 10(2), e0117476. 
Neill, R. D., Blair, C., Best, P., McGlinchey, E., \& Armour, C. (2021, 2021/03/20). Media consumption and mental health during COVID-19 lockdown: a UK cross-sectional study across England, Wales, Scotland and Northern Ireland. Journal of Public Health. https://doi.org/10.1007/s10389-021-01506-0

Pan, W., Liu, D., \& Fang, J. (2021, 2021-March-01). An Examination of Factors Contributing to the Acceptance of Online Health Misinformation [Brief Research Report]. Frontiers in psychology, 12(524). https://doi.org/10.3389/fpsyg.2021.630268

Pekrun, R. (2006, 2006/12/01). The Control-Value Theory of Achievement Emotions: Assumptions, Corollaries, and Implications for Educational Research and Practice. Educational Psychology Review, 18(4), 315-341. https://doi.org/10.1007/s10648-0069029-9

Petty, R. E., \& Cacioppo, J. T. (2012). Communication and persuasion: Central and peripheral routes to attitude change. Springer Science \& Business Media.

Pew. (2021). Those on ideological right favor fewer COVID-19 restrictions in most advanced economies. Retrieved 10 September 2021 from https://www.pewresearch.org/facttank/2021/07/30/those-on-ideological-right-favor-fewer-covid-19-restrictions-in-mostadvanced-economies/

Pieschl, S., Budd, J., Thomm, E., \& Archer, J. (2021, Jul). Effects of Raising Student Teachers' Metacognitive Awareness of Their Educational Psychological Misconceptions.

Psychology Learning and Teaching-Plat, 20(2), 214-235. https://doi.org/10.1177/1475725721996223

Prinz, A., Golke, S., \& Wittwer, J. (2019, Aug). Refutation Texts Compensate for Detrimental Effects of Misconceptions on Comprehension and Metacomprehension Accuracy and Support Transfer. Journal of educational psychology, 111(6), 957-981. https://doi.org/10.1037/edu0000329

Renström, E. A., \& Bäck, H. (2021). Emotions during the Covid-19 pandemic: Fear, anxiety, and anger as mediators between threats and policy support and political actions. Journal of Applied Social Psychology.

Roozenbeek, J., \& van der Linden, S. (2019). Fake news game confers psychological resistance against online misinformation. Palgrave Communications, 5, 1-10.

Ryan, R. M., \& Deci, E. L. (2017). Self-determination theory: Basic psychological needs in motivation, development, and wellness. Guilford Publications.

Sailer, M., Hense, J. U., Mayr, S. K., \& Mandl, H. (2017). How gamification motivates: An experimental study of the effects of specific game design elements on psychological need satisfaction. Computers in Human Behavior, 69, 371-380. 
Sardi, L., Idri, A., \& Fernández-Alemán, J. L. (2017). A systematic review of gamification in eHealth. Journal of biomedical informatics, 71, 31-48.

Sharot, T., \& Sunstein, C. R. (2020). How people decide what they want to know. Nature Human Behaviour, 4(1), 14-19.

Sinatra, G. M., \& Seyranian, V. (2015). Warm change about hot topics: The role of motivation and emotion in attitude and conceptual change about controversial science topics. In Handbook of educational psychology (pp. 259-270). Routledge.

Smith, L. E., Duffy, B., Moxham-Hall, V., Strang, L., Wessely, S., \& Rubin, G. J. (2021). Anger and confrontation during the COVID-19 pandemic: a national cross-sectional survey in the UK. Journal of the Royal Society of Medicine, 114(2), 77-90.

Steindl, C., Jonas, E., Sittenthaler, S., Traut-Mattausch, E., \& Greenberg, J. (2015). Understanding psychological reactance. Zeitschrift für Psychologie.

Suldovsky, B. (2016). In science communication, why does the idea of the public deficit always return? Exploring key influences. Public Understanding of Science, 25(4), 415-426.

Thacker, I., Sinatra, G. M., Muis, K. R., Danielson, R. W., Pekrun, R., Winne, P. H., \& Chevrier, M. (2020, Aug). Using Persuasive Refutation Texts to Prompt Attitudinal an Conceptual Change. Journal of educational psychology, 112(6), 1085-1099. https://doi.org/10.1037/edu000434

Tippett, C. D. (2010). Refutation text in science education: A review of two decades of research. . International journal of science and mathematics education, 8(6), 951-970.

Trevors. (2021). The Roles of Identity Conflict, Emotion, and Threat in Learning from Refutation Texts on Vaccination and Immigration. Discourse Processes. https://doi.org/10.1080/0163853x.2021.1917950

Trevors, G., \& Duffy, M. C. (2020, Oct). Correcting COVID-19 Misconceptions Requires Caution. Educational Researcher, 49(7), 538-542, Article 0013189x20953825. https://doi.org/10.3102/0013189x20953825

Trevors, G., Kendeou, P., \& Butterfuss, R. (2017). Emotion Processes in Knowledge Revision. Discourse Processes, 54(5-6), 406-426. https://doi.org/10.1080/0163853x.2017.1312201

Trevors, G. J., Muis, K. R., Pekrun, R., Sinatra, G. M., \& Winne, P. H. (2016, Sep). Identity and Epistemic Emotions During Knowledge Revision: A Potential Account for the Backfire Effect. Discourse Processes, 53(5-6), 339-370. https://doi.org/10.1080/0163853x.2015.1136507

van der Linden, S. (2019). Countering science denial. Nature Human Behaviour, 3(9), 889-890. 
Vosniadou, S., Ioannides, C., Dimitrakopoulou, A., \& Papademetriou, E. (2001). Designing learning environments to promote conceptual change in science. Learning and Instruction, 11(4-5), 381-419. https://doi.org/10.1016/S0959-4752(00)00038-4

Walter, N., Cohen, J., Holbert, R. L., \& Morag, Y. (2020, 2020/05/03). Fact-Checking: A MetaAnalysis of What Works and for Whom. Political Communication, 37(3), 350-375. https://doi.org/10.1080/10584609.2019.1668894

Walter, N., \& Murphy, S. T. (2018, 2018/07/03). How to unring the bell: A meta-analytic approach to correction of misinformation. Communication Monographs, 85(3), 423-441. https://doi.org/10.1080/03637751.2018.1467564

WHO. (2021). Infodemic. Retrieved 10 September 2021 from https://www.who.int/healthtopics/infodemic

Yang, K.-C., Pierri, F., Hui, P.-M., Axelrod, D., Torres-Lugo, C., Bryden, J., \& Menczer, F. (2021). The COVID-19 Infodemic: Twitter versus Facebook. Big Data \& Society, 8(1), 20539517211013861. 
Table 1

Self-reported race and ethnicities.

\begin{tabular}{lrr}
\hline First Nations & 268 & $1 \%$ \\
Inuit & 21 & $0 \%$ \\
Métis & 232 & $1 \%$ \\
East Asian & 435 & $2 \%$ \\
South Asian & 321 & $1 \%$ \\
South-East Asian & 277 & $1 \%$ \\
Black/African & 90 & $0 \%$ \\
Black/Caribbean & 85 & $0 \%$ \\
Black/North American & 37 & $0 \%$ \\
Latin American & 199 & $1 \%$ \\
Latinx & 30 & $0 \%$ \\
White/European & 7071 & $28 \%$ \\
White/North American & 14158 & $57 \%$ \\
Middle Eastern & 148 & $1 \%$ \\
Mixed Heritage & 745 & $3 \%$ \\
I don't see myself represented here & 516 & $2 \%$ \\
Abstain & 292 & $1 \%$ \\
\hline
\end{tabular}


Table 2

Self-reported gender.

\begin{tabular}{lrr}
\hline Female & 18549 & $70 \%$ \\
Male & 6952 & $26 \%$ \\
Non-binary & 163 & $1 \%$ \\
Gender-Expansive & 34 & $0 \%$ \\
other & 240 & $1 \%$ \\
Two-spirit & 46 & $0 \%$ \\
Transgender & 54 & $0 \%$ \\
I don't see myself represented here & 139 & $1 \%$ \\
Transsexual & 10 & $0 \%$ \\
Genderqueer & 72 & $0 \%$ \\
Intersex & 7 & $0 \%$ \\
Abstain & 202 & $1 \%$ \\
\hline
\end{tabular}


Table 3

Self-reported age.

\begin{tabular}{lrr}
\hline $18-24$ & 1928 & $7 \%$ \\
$25-34$ & 2523 & $10 \%$ \\
$35-44$ & 2945 & $11 \%$ \\
$45-54$ & 3969 & $15 \%$ \\
$55-64$ & 7230 & $28 \%$ \\
$65-74$ & 5819 & $22 \%$ \\
$75-84$ & 1276 & $5 \%$ \\
$85+$ & 199 & $1 \%$ \\
Abstain & 350 & $1 \%$ \\
\hline
\end{tabular}


Table 4

Descriptive and correlational statistics between knowledge, emotion, and key outcomes.

\begin{tabular}{|c|c|c|c|c|c|c|c|}
\hline & Correct & Happy & Angry & Anxious & Skeptical & Retention & Policy \\
\hline Correct & $\begin{array}{l}.79 \\
(.27)\end{array}$ & & & & & & \\
\hline Нарру & $.156^{* * *}$ & $\begin{array}{l}.34 \\
(.46)\end{array}$ & & & & & \\
\hline Angry & $-.119 * *$ & $-.228 * *$ & $\begin{array}{l}.09 \\
(.28)\end{array}$ & & & & \\
\hline Anxious & $.052 * *$ & $-.518 * *$ & $-.233 * *$ & $\begin{array}{l}.34 \\
(.46)\end{array}$ & & & \\
\hline Skeptical & $-.154 * *$ & $-.386 * *$ & $-.168 * *$ & $-.392 * *$ & $\begin{array}{l}.23 \\
(.40)\end{array}$ & & \\
\hline Retention & $.266^{* *}$ & $.080 * *$ & $-.054 * *$ & .013 & $-.068 * *$ & $\begin{array}{l}.87 \\
(.34)\end{array}$ & \\
\hline Policy & $.235^{* *}$ & $.150 * *$ & $-.071 * *$ & $.106 * *$ & $-.242 * *$ & $.101 * *$ & $\begin{array}{l}.83 \\
(.24) \\
\end{array}$ \\
\hline
\end{tabular}

Note. Means and standard deviations (in paratheses) on diagonal. Scale: 0-1.

$* * p<.01$ 
Table 5

Difference between baseline and game conditions on proportional emotional reactions.

\begin{tabular}{cccccccc}
\hline Emotion & Condition & $M$ & $S D$ & $t$ & $d f$ & $p$ & $d$ \\
\hline Happy & Control & $36 \%$ & $40 \%$ & 2.95 & 22952 & .003 & .041 \\
& Game & $38 \%$ & $48 \%$ & & & & \\
Angry & Control & $12 \%$ & $27 \%$ & -5.88 & 22952 & $<.001$ & -.081 \\
& Game & $10 \%$ & $29 \%$ & & & & \\
Anxious & Control & $23 \%$ & $35 \%$ & 11.64 & 22952 & $<.001$ & .161 \\
& Game & $30 \%$ & $45 \%$ & & & & \\
Skeptical & Control & $29 \%$ & $38 \%$ & -11.04 & 22952 & $<.001$ & -.153 \\
& Game & $23 \%$ & $41 \%$ & & & & \\
\hline
\end{tabular}


GAMIFYING REFUTATIONS

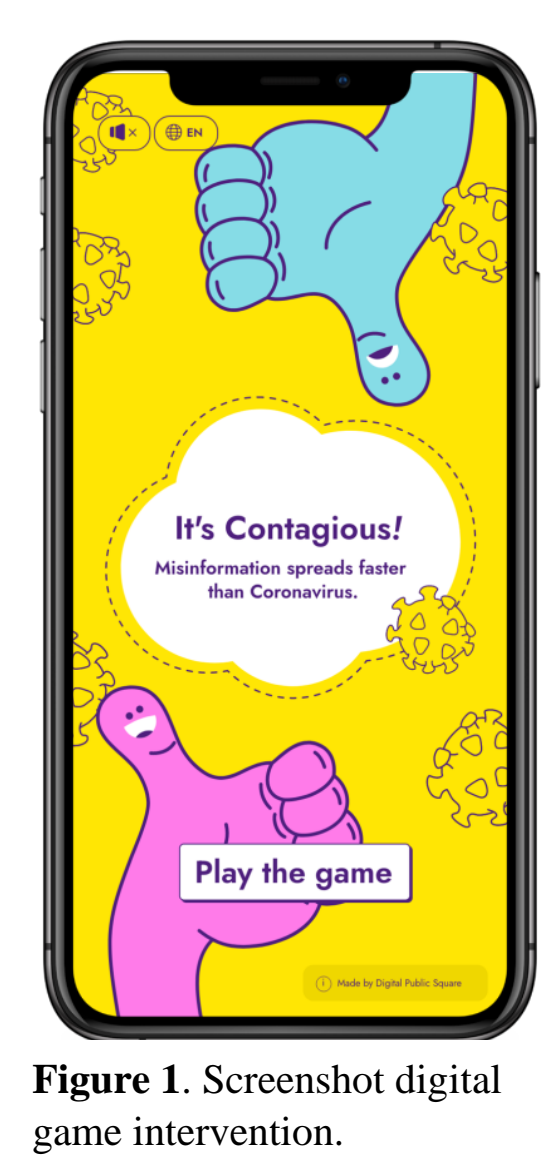

